\title{
Experimental Study on the Fracture Behaviors Effect of Stress Conditions on the Fracture of Shale by Super- Critical Carbon Dioxide
}

\begin{abstract}
Guojun Liu ${ }^{1,2 *}$, Yuan Zhao ${ }^{3,4 *}$ and Yugang Cheng ${ }^{5}$
${ }^{1}$ Hunan Engineering Research Center of Structural Safety and Disaster Prevention for Urban Underground Infrastructure, Hunan City University, Yiyang, China, ${ }^{2}$ College of Civil Engineering and Mechanics, Xiangtan University, Xiangtan, China, ${ }^{3}$ Sinohydro Bureau 8 Co. LTD., POWERCHINA, Changsha, China, ${ }^{4}$ Department of Hydraulic Engineering, Tsinghua University, Beijing, China,

${ }^{5}$ State Key Laboratory of Mountain Bridge and Tunnel Engineering, Chongqing Jiaotong University, Chongqing, China
\end{abstract}

This paper examines the fracture propagation problems of supercritical carbon fracturing in low permeability shale. Acoustic emission monitoring and computerized tomography (CT) scanning methods were used to study the influence of initial stress ratios on crack

OPEN ACCESS

Edited by:

Guowen Xu,

Colorado School of Mines,

United States

Reviewed by:

Delei Shang,

Shenzhen University, China

Yong $\mathrm{Li}$,

Chongqing University, China

*Correspondence:

Guojun Liu

liuguojun@hncu.edu.cn

Yuan Zhao

zhaoyuan@cqu.edu.cn

Specialty section:

This article was submitted to

Carbon Capture, Utilization and

Storage,

a section of the journa

Frontiers in Energy Research

Received: 23 August 2021

Accepted: 29 October 2021

Published: 10 December 2021

Citation:

Liu G, Zhao Y and Cheng Y (2021)

Experimental Study on the Fracture

Behaviors Effect of Stress Conditions

on the Fracture of Shale by Super-

Critical Carbon Dioxide.

Front. Energy Res. 9:763052.

doi: 10.3389/fenrg.2021.763052 initiation and propagation crack in fracturing experiments. The results show that crack initiation pressure and crack morphology are very different under different stress conditions. Under the condition of constant confining pressure, when the initial stress ratio $\lambda=1$, cracks are mainly in a horizontal direction; while for an initial stress ratio of $\lambda<1$, cracks are mainly in a vertical direction. With the decrease of $\lambda$, crack initiation pressure, reopening pressure, and fracturing liquid volume also decrease, and crack propagation is not as obvious. According to CT scanning results, the crack propagation direction is the same as the maximum principal stress, and fewer cracks are initiated with a smaller initial stress ratio. Based on the acoustic emission characteristics, the fracturing process (including crack initiation, propagation, and closure), can be divided into three stages: 1) the pressure accumulation in the wellbore, 2) Pump Closure; and 3) crack reopening. This study provides the basis for a reasonable selection of shale gas fracturing formation and geo-sequestration of greenhouse gas $\mathrm{CO}_{2}$.

Keywords: shale gas, super-critical carbon dioxide, carbon sequestration, mechanical characteristics, acoustic emission

\section{INTRODUCTION}

China is very rich in shale gas, with resources of $3.608 \times 1013 \mathrm{~m}^{3}$, which has great potential to develop the shale gas industry (Wang, 2011). However, as the shale matrix has characteristics of ultra-low permeability, it is necessary to explore the relationship between natural fractures and artificial fracturing in forming a fracture network and a high permeable path to increase production. At present, hydraulic fracturing technology is the main method that greatly improves the yield of shale gas (Jin, et al., 2012; Jin and Shah, 2013); however, the process consumes a large amount of water during hydraulic fracturing (Vengosh et al., 2014; Brantley et al., 2014) Furthermore, chemical additives in the fracturing fluids may cause serious pollution to the reservoir and surrounding environment as hydraulic fracturing in China could cause swelling clays to obstruct gas channels (Small et al., 2014; Huang et al., 2015), which can easily decrease permeability and gas production 
(Lai et al., 2005) Additionally, most favorable exploration areas are short of water, meaning non-aqueous fracturing technology is of great significance for the exploration and development of shale gas in China. In recent years, some scholars have put forward supercritical $\mathrm{CO}_{2}$ (when temperature and pressure are above $304.1 \mathrm{~K}$ and $7.38 \mathrm{MPa}, \mathrm{CO}_{2}$ will reach a supercritical state) as a new fracturing fluid for shale gas development (Ishida et al., 2012; Chen L. Q. et al., 2015; Middleton et al., 2015) S Supercritical $\mathrm{CO}_{2}$ is beneficial for improving the permeability of the reservoir and using supercritical $\mathrm{CO}_{2}$, as the fracturing fluid reduces reservoir damage and can obtain higher oil and gas recovery (Gupta et al., 2005; Kolle, 2000). Domestic research also shows that supercritical $\mathrm{CO}_{2}$ can make clay mineral dehydration shrink the shale gas reservoir as porosity increases, and effectively protects the reservoir. In addition, the adsorption capacity of shale to $\mathrm{CO}_{2}$ is much larger than $\mathrm{CH}_{4}$, which can effectively replace $\mathrm{CH}_{4}$ in shale and improve the recovery of shale gas, while finally achieving $\mathrm{CO}_{2}$ geological sequestration (Xie et al.,.2014). It is therefore of great scientific significance to study the mechanical characteristics and failure mechanisms of shale gas in the supercritical $\mathrm{CO}_{2}$ fracturing process, to find a suitable method for the development of shale gas reservoirs in China.

Hubbert and Willis (1972) first proposed crack initiation criteria for longitudinal fractures and suggested that fracture pressure was related to horizontal principal stress, rock tensile strength, and pore pressure. They outline that fracture pressure has nothing to do with the size, elasticity parameters of the rock, or vertical principal stress. Haimson and Fairhurst (1967) considered the diafiltration effect of the rock to improve the rupture pressure calculation formula, observing that the formation of cracks mainly depends on the stress state on the borehole wall (Zubkov et al., 2007; Schmidt and Zoback, 1989) considered the effect of porosity and Poisson's ratio on initiation pressure, which improved the Hubbert and Willis criteria, and proposed the initiation criteria of permeable rock formation and non-permeable rock formation. Yang et al. (2014) pointed out the importance of supercritical $\mathrm{CO}_{2}$ compressibility by studying the pore pressure of supercritical $\mathrm{CO}_{2}$ wave propagation in saturated pore media. Chen Y. et al. (2015) considered the characteristics of low viscosity, high compressibility, and the low-pressure rate of supercritical $\mathrm{CO}_{2}$ fluid, and the supercharging rate model of supercritical $\mathrm{CO}_{2}$ fluid in wellbore was established, thus concluding that the fracturing pressure of supercritical $\mathrm{CO}_{2}$ is $75.5 \%$ lower than that of conventional hydraulic fracturing.

Current research on supercritical $\mathrm{CO}_{2}$ fracturing is relatively rare. The deformation and failure characteristics of shale and the mechanism of crack propagation at the coupling of the original rock stress field and fluid field are key problems that need to be solved urgently in the process of shale gas exploitation. The original stress state, rock tensile strength, and development degree of natural crack are important factors that influence fracture morphology. Therefore, a three-axis fracturing indoor experiment was carried out to simulate supercritical $\mathrm{CO}_{2}$ fracturing shale under different stress conditions, and acoustic emission detection technique and CT scanning were combined to investigate initial fracturing condition and analyze the process of crack formation, crack propagation, and crack morphological changes of fracturing shale under different stress conditions. The results of this research provide important parameters to reveal the mechanism that in situ stress states influence the law of shale crack propagation.

\section{TEST EQUIPMENT AND SOLUTIONS}

\section{Specimen Preparation}

The shale specimens were taken from an outcrop of the lower Silurian Longmaxi formation, located in the Changning region of the Sichuan Basin. The total organic carbon (TOC) content was $4.18 \%$ and the vitrinite reflectance (Ro) was $2.36 \%$, the uniaxial tensile strength was $9.2 \mathrm{MPa}$, the elastic modulus was $16.0 \mathrm{GPa}$, and Poisson's ratio was 0.31 . The shale was mainly composed of quartz and illite, with the addition of calcite, feldspar, dolomite, chlorite, pyrite, and other minerals. The average value of the total amounts of brittle minerals was about $70.54 \%$, which is similar to typical shale gas basins in North America.

To reduce the dispersion of the samples of the test results, they were drilled from the same piece of shale. The drilling direction was perpendicular to the bedding plane, and samples with smooth ends and no surface cracks were selected for processing into cylinder specimen $(100 \mathrm{~mm}$ in diameter and $200 \mathrm{~mm}$ in length, axial and radial pressure were applied respectively), as shown in Figure 1. Before the fracturing experiment, an axial central borehole with an 8-mm diameter was drilled to a depth of $140 \mathrm{~mm}$. An injection pipe was inserted into the borehole to ensure the tightness of the system during the experiment.

The deviation of height and diameter in samples was controlled at $\pm 0.3 \mathrm{~mm}$, and the deviation of flatness was controlled at $\pm 0.02 \mathrm{~mm}$ in the process. The shale samples were tested by a sonic wave before the fracturing experiment, the samples with relatively closer wave velocity were selected. The basic physical parameters of experimental shale samples are shown in Table 1.

\section{Test Equipment}

The supercritical $\mathrm{CO}_{2}$ fracturing shale and increased permeability experimental device were independently developed by Chongqing University (Figure 2A). The experimental device was specifically designed for supercritical $\mathrm{CO}_{2}$ fracturing and was composed of six subsystems: an air supply system, $\mathrm{CO}_{2}$ injection system, triaxial loading and control system, temperature control system (oil bath), acoustic emission monitoring system, and a data collecting system.

Figure 2 shows the test system. This test was developed to study the fracture law of shale caused by supercritical $\mathrm{CO}_{2}$ and explore the influence law of supercritical $\mathrm{CO}_{2}$ on shale initial cracking pressure, furthering research on self-developing supercritical $\mathrm{CO}_{2}$ cracking using an increasing permeability test device (Zhou et al., 2016), for shale gas reservoirs. The system is composed of six parts: Gas source supply system, $\mathrm{CO}_{2}$ boosting control system, triaxial servo loading system, temperature control system, acoustic emission monitoring system, and data acquisition system. It can simulate an 


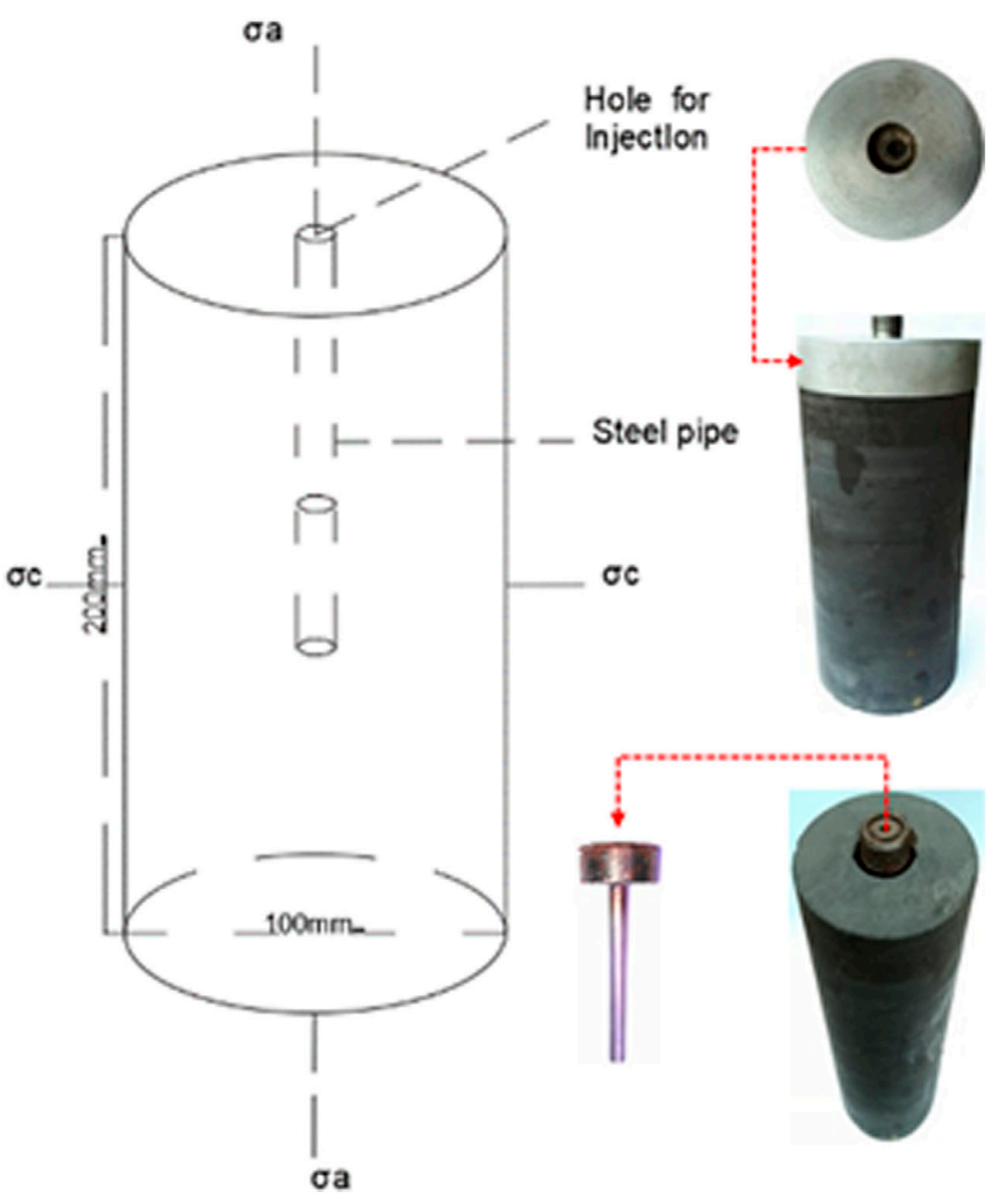

FIGURE 1 | Diagram of drilling hole and preparation process of fracturing sample.

TABLE 1 | Basic physical parameters of experimental samples.

Sample number

$1\left(\mathrm{~S}_{1}\right)$

$2\left(S_{2}\right)$

$3\left(\mathrm{~S}_{3}\right)$

$4\left(\mathrm{~S}_{4}\right)$
Density $\left(\mathbf{g} . \mathrm{cm}^{-3}\right)$

2.59

2.56

2.52

2.58
Porosity (\%)

$$
\begin{aligned}
& 3.5569 \\
& 3.6578 \\
& 3.6925 \\
& 3.5869
\end{aligned}
$$

Longitudinal velocity $\left(\mathrm{m} \cdot \mathrm{s}^{-1}\right)$

$$
\begin{aligned}
& 4,580 \\
& 4,540 \\
& 4,500 \\
& 4,600
\end{aligned}
$$

experiment of fracture propagation laws in the process of supercritical $\mathrm{CO}_{2}$ fracturing shale under the coupling of multiple fields and collect the stress-strain relationship and acoustic emission signals in real time during the process of the shale fracture.

1) Figure $2 \mathbf{A}$ is a High precision plunger pump, which is mainly used to provide high-pressure $\mathrm{CO}_{2}$ fluid. The plunger pump can provide continuous, stable and pulse free flow, and can carry out constant pressure and constant flow operation. The maximum pressure is $50 \mathrm{MPa}$ and the maximum capacity is
$266 \mathrm{ml}$. Supercritical $\mathrm{CO}_{2}$ is a critical state in which the temperature and pressure of $\mathrm{CO}_{2}$ meet the requirements of $31.04^{\circ} \mathrm{C}$ and $7.38 \mathrm{mpa}$ respectively. The plunger pump can fully meet the pressure control range and pressure mode required by the experimental process. The plunger pump adopts a constant pressure mode to load.

2) Figure $2 \mathbf{B}$ is a multi field coupling physical simulation test machine, which can realize the simulation test of real shale reservoir temperature, pressure, and stress field. After all the three-axis servo loading devices are lifted to the constant temperature oil bath, the stress is loaded when the 

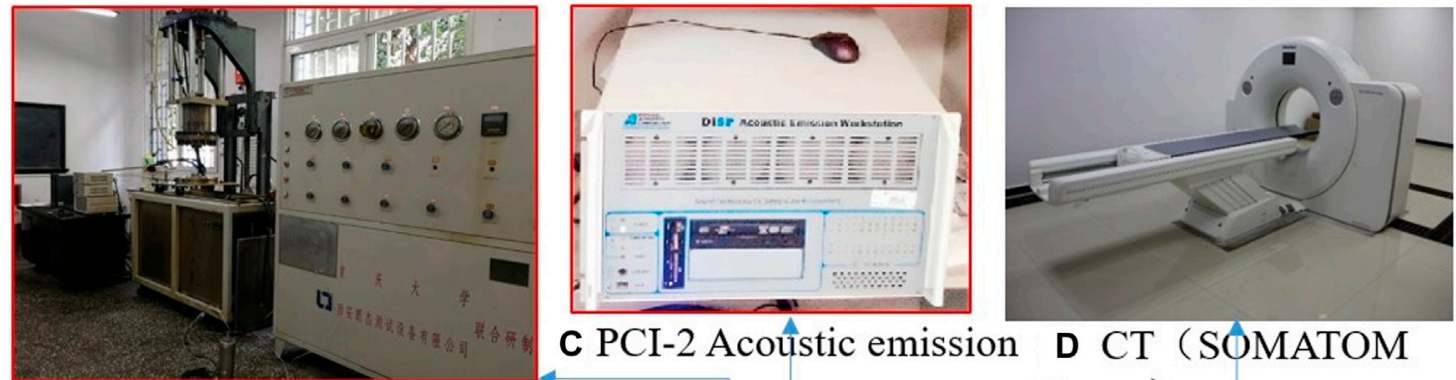

c PCI-2 Acoûstic emission D CT (SOMATOM

B Multi field coupling experiment machine

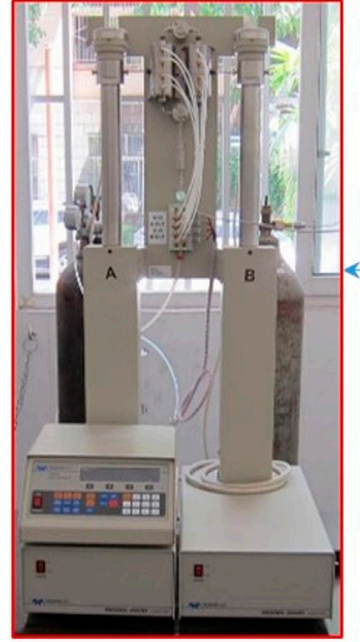

A High precision plunger pump

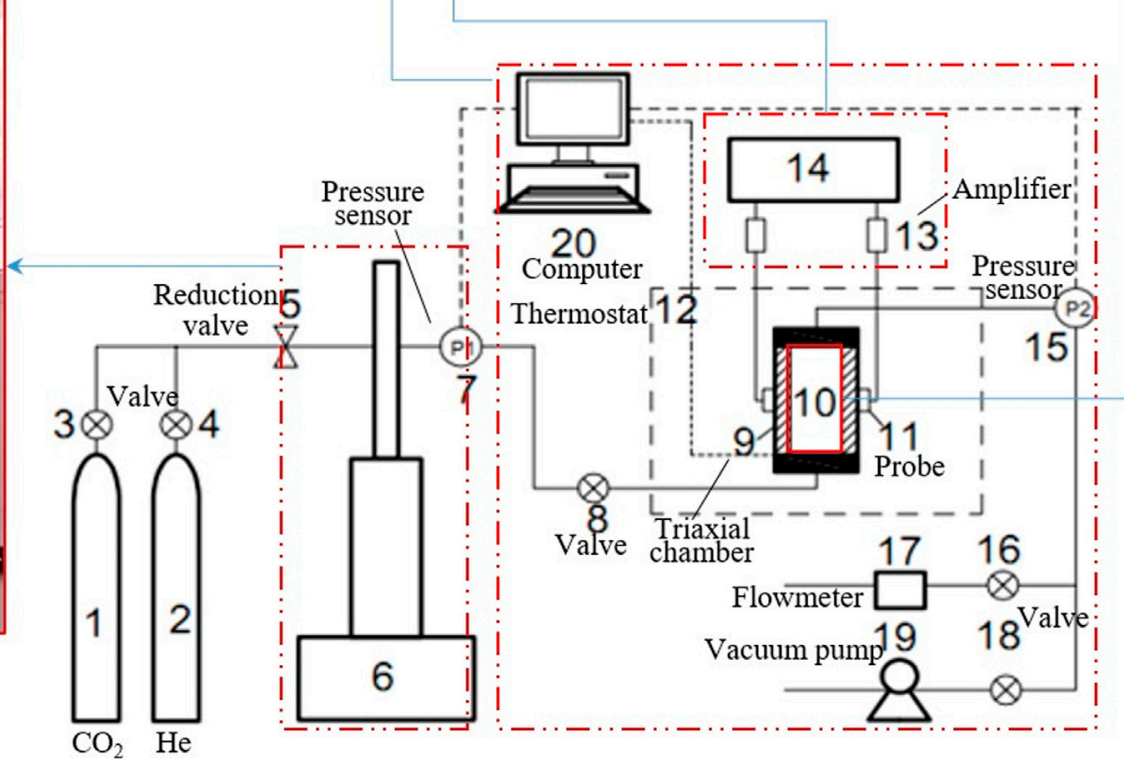

FIGURE 2|Schematic diagram of supercritical $\mathrm{CO}_{2}$ fracturing shale test system. (A) High precision plunger pump. (B) Multi-field coupling experiment machine. (C) $\mathrm{PCl}-2$ Acoustic emission. (D) CT (SOMTOM Scope)

temperature is constant to the set temperature. The pressure field mainly considers supercritical $\mathrm{CO}_{2}$ fluid, and the gas inlet and outlet ends are all produced. The pressure sensor is used to monitor the change of fluid pressure during the experiment. The maximum load axial pressure of the system is $100 \mathrm{MPa}$, the maximum confining pressure is $30 \mathrm{MPa}$, the maximum fluid pressure can be provided at $20 \mathrm{MPa}$, the maximum axial displacement is $60 \mathrm{~mm}$, the maximum circumferential deformation is $10 \mathrm{~mm}$, and the axial confining pressure adopts hydraulic loading, which can meet the requirements of the experiment. The transformation and upgrading of the test system provide a new means for the study of shale mechanical properties and fluid seepage law under the condition of multi field coupling, which can promote more in-depth study on the geological storage of carbon dioxide and the efficient exploitation of shale gas.

3) Figure $2 \mathrm{C}$ is a PCI-2 acoustic emission system, which has the advantages of computerization, full digitalization, multichannel, low noise, low threshold value, ultra fast processing speed, and reliable stability. The 8-channel disp acoustic emission positioning system is used to monitor the fracture initiation and extension information, and the acoustic emission data, the event distribution location in the three-dimensional acoustic emission positioning, and the rock stress-strain curve are used to analyze the mechanical behavior of shale fracture propagation.

TABLE 2 | The test parameters of supercritical $\mathrm{CO}_{2}$ fracturing experiment.

\begin{tabular}{|c|c|c|c|c|}
\hline Sample number & Vertical stress (MPa) & Horizontal stress (MPa) & $\begin{array}{c}\text { Initial } \\
\text { stress ratio }(\lambda)\end{array}$ & $\begin{array}{l}\text { Injection r } \\
\mathrm{CO}_{2}(\mathrm{ml} \cdot \mathrm{m}\end{array}$ \\
\hline $1\left(S_{1}\right)$ & 10 & 10 & 1 & 20 \\
\hline $2\left(S_{2}\right)$ & 20 & 10 & 0.5 & 20 \\
\hline $3\left(S_{3}\right)$ & 30 & 10 & 0.33 & 20 \\
\hline $4\left(S_{4}\right)$ & 40 & 10 & 0.25 & 20 \\
\hline
\end{tabular}


4) Figure 2D is the medical CT produced by SIEMENS, which can perform non-destructive testing of rocks.

\section{Test Scheme}

To reach the supercritical state of $\mathrm{CO}_{2}$, the experiment temperature was kept constant at $308 \mathrm{~K}$. To simulate the influence of different stress conditions on failure modes and initiation pressures of crack, horizontal stress remained constant, the initial stress ratio (the ratio of horizontal stress and vertical stress) was changed by changing vertical stress during the experiment. The confining pressure (horizontal stress) was constant at $10 \mathrm{MPa}$, and the axial (vertical stress) was set at 10,20,30, and $40 \mathrm{MPa}$, respectively. In the process of supercritical $\mathrm{CO}_{2}$ fracturing, acoustic emission signals were monitored simultaneously, and the experimental scheme is shown in Table 2.

Fracturing and re-fracturing experiments were carried out to simulate the fracturing and re-fracturing process. Therefore, supercritical $\mathrm{CO}_{2}$ injection was divided into two stages, the injection rate of $\mathrm{CO}_{2}$ fluid was constant at $20 \mathrm{ml} \cdot \mathrm{min}^{-1}$ at each stage. First, $\mathrm{CO}_{2}$ was injected continuously until the pressure was no longer elevated, and after the completion of fracturing, when the pressure inside the specimen decreased, the pump pressure stopped immediately. Second, when the internal pressure of the crack achieved balance, $\mathrm{CO}_{2}$ fluid continued to be injected.

Before and after the fracturing test, the specimens were photographed using a high definition digital camera and CT scanning to obtain surface and internal crack characteristics of the samples before and after fracturing. The CT scans of each specimen, along with samples in a vertical direction $(200 \mathrm{~mm})$ of $0.75 \mathrm{~mm}$ thickness to form a layer.

\section{ANALYSIS OF EXPERIMENTAL RESULTS}

\section{Analysis of Pump Pressure Curve}

The acoustic emission count-time curve and pump pressure-time curve during shale fracturing experiments are shown in Figure 3. The overall trend of the pump pressure curve and acoustic emission curve of the four specimens was similar. The process can be divided into three stages:

\section{The Stage of Pressure Accumulation in Wellbore}

The initial pressure of failure of shale can be defined as peak pressure at this stage. Carbon dioxide fluid, an effective fracturing fluid, first gathered in an artificial cavity pocket with the gradual injection of fluid, the pressure of carbon dioxide in the fracturing chamber grew sharply, before the carbon dioxide fluid started to squeeze into the pore and fissure system around the wellbore. When the pressure reached a certain value, the pressure of fracturing fluid growth rate became relatively slow due to the diffusion of pressure in cracks and pores. The small amount of acoustic emission signals produced in this phase indicate that the native cracks of shale began to open gradually under the effect of carbon dioxide fluid along with the formation of micro cracks, but shale had not yet formed macroscopic cracks through this
A

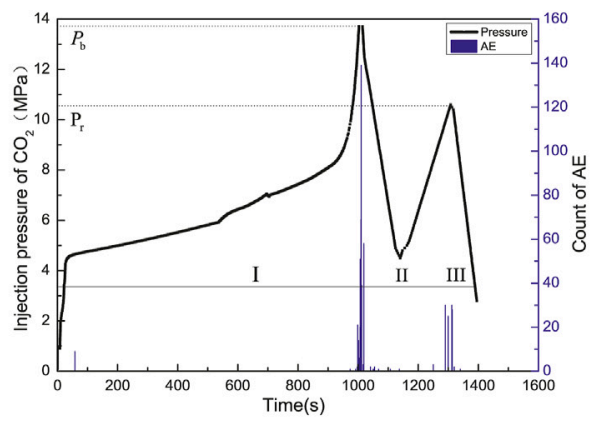

The relationship curve between acoustic emission count -time and pump pressure- time of $\mathrm{S}_{1}$

B

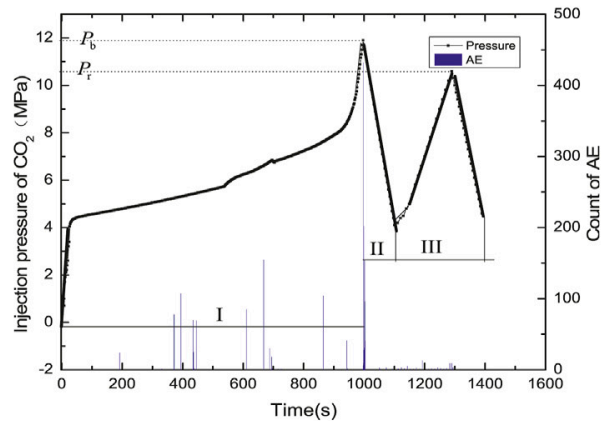

The relationship curve between acoustic emission count-time and pump pressure-time of $\mathrm{S}_{2}$ C

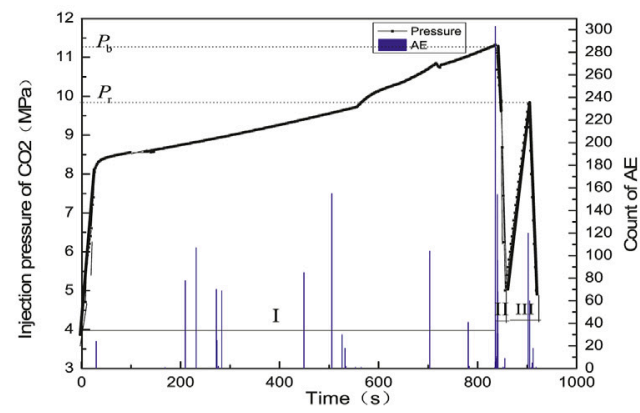

The relationship curve between acoustic emission count -time and pump pressure- time of $\mathrm{S}_{3}$ D

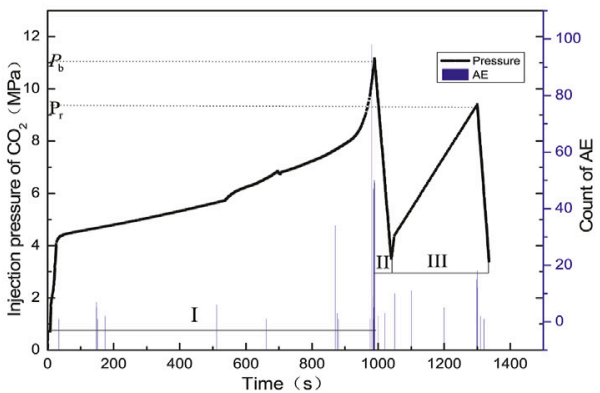

FIGURE 3 | The relationship curves between acoustic emission counttime and pump pressure-time of samples. (A) The relationship curve between acoustic emission count-time and pump pressure-time of $\mathrm{S}_{1}$. (B) The relationship curve between acoustic emission count-time and pump pressure-time of $S_{2}$. (C) The relationship curve between acoustic emission count-time and pump pressure-time of $S_{3}$. (D) The relationship curve between acoustic emission count-time and pump pressure-time of $\mathrm{S}_{4}$ 
process. Carbon dioxide fluid pressure still rose and its increase rate began to increase faster after the pore and fissure space was full of carbon dioxide with a continuous injection of fluid until the shale failed, and pump pressure vs. time curve reached the first peak value. A large number of acoustic emission counts were found during the peak value of pressure, which indicates that fractures were generated and extended dramatically, and transfixion cracks were formed.

\section{Stage of Pump Closure}

The pressure of fracturing fluid decreased rapidly after the closure of the fracturing pump, as crack coalescence formed in the shale specimens and the seepage channel had been generated, which resulted in the faster spread of the fluid inside the crack and pressure dropping quickly in the fracture until finally, the pressure remained at a certain value. The acoustic emission signal was weak and the counts were relatively small (or even none), which showed that hardly any new cracks were generated at this stage and mainly show the closure of the generated fracture.

\section{Crack Reopening Stage}

The fracturing fluid of supercritical carbon dioxide was continually injected into the opened cracks by opening the plunger pump after the pressure of the fracturing chamber reached the balance value. The pressure of the fracture increased dramatically at the same time, the fractured cracks reopened after the fracture stop closure, and crack pressure reached the second peak value, which reached $\mathrm{Pr}$. The AE counts of repeated fracturing reduced significantly compared to the initial fracturing, but it still had a strong acoustic emission signal, which indicates that the original cracks continue to propagate and extend at the second fracturing process and many secondary cracks were generated.

The results of supercritical $\mathrm{CO}_{2}$ fluid fracturing shale are shown in Table 3. In combination with Table 1 and Table 2, it can be concluded that the initiation pressure of shale is always higher than horizontal stress; however, the stress of repeated fracturing is close to horizontal stress $(10 \mathrm{MPa})$. With the decrease of $\lambda$, the initiation pressure of shale, the stress of repeated fracturing, and the amount of fracturing fluid decreased. Among them, the initiation pressure of Specimen 1 was highest $(13.7 \mathrm{MPa})$, and the stress of repeated fracturing on Specimen 4 was the smallest $(9.4 \mathrm{MPa})$.

According to first strength theory, during the supercritical $\mathrm{CO}_{2}$ fluid fracturing process when the fluid pressure exceeds the stress required for the cracking of the rock at the hole wall, cracks are generated at the wall of the hole, and the occurrence of cracks is related to the type of fluid, the size of ground stress and the physical and mechanical properties of the rock. In this paper, with a constant confining pressure and the greater the vertical stress, the smaller the initial stress ratio and the lower the stress of the rock cracking at the hole wall, which results in a decrease in the initiation pressure with the decrease of the initial stress ratio (Zhao et al., 2015). The relationship between the initiation pressure and the initial stress ratio of the shale specimens is shown in Figure 4, which shows that the initiation pressure increases with the increase of the initial stress ratio and that there is a linear relationship between the initiation pressure and the initial stress ratio, which can be fitted to $y=3.7 x+10\left(R^{2}=0.998\right)$.

When the shale samples initial pressure relief, the samples will reach the second pressure peak, continuing to inject $\mathrm{CO}_{2}$. The reopening pressure can be obtained. As shown in Table 3. The reopening pressure of the cracks are lower than the initial pressure of the crack, which is due to damage to the shale specimen and forms a certain crack network during the initial fracturing as the strength of the shale itself was reduced. In the second fracturing, the crack continued to propagate based on the existing crack. This can also be verified in the CT scanning image where the initial stress ratio was different, as the number of fractures formed and the crack volume space were different in terms of fracturing. The different crack volumes led to a difference in the amount of $\mathrm{CO}_{2}$ fluid entering the crack pore space, so different initial stress ratios in addition to the impact of initiation pressure also lead to a difference in the amount of fracturing fluid.

\section{CT Scanning and the Crack Characteristics of Shale Samples}

From the obtained CT scanning images of the shale samples, each specimen $\left(\mathrm{S}_{1}-\mathrm{S}_{4}\right)$ was selected from two groups of CT scanning images in the vertical and parallel direction of the axial section before and after fracturing, with a total of 16 images shown in Figure 5.

The CT scanning image of the initial stress ratio at 1 is shown in Figure 5A. Some new cracks were created at the level of the vertical wellbore axis, while transverse cracks were found at the level of the parallel wellbore axis, which suggests that cracks mainly extend from the center of the wellbore to the horizontal direction of the wellbore, at the same vertical stress and horizontal stress (Figure 5A).

In Figures 5B-D, there were no obvious cracks in the shale specimens and the shales kept integrity before fracturing. In comparison to Figure 5A, some cracks were detected in both the vertical and parallel wellbore sections after fracturing in (Figures 5B-D), and cracks and fractures were similar to the end face of the

TABLE 3 | Experimental results of shale specimens.

\begin{tabular}{lccc}
\hline Sample number & Breaking time (s) & Initiation pressure (MPa) & $\begin{array}{c}\text { Consumed } \\
\text { fluid volume (m) }\end{array}$ \\
\hline $1\left(S_{1}\right)$ & & & 1,192 \\
$2\left(S_{2}\right)$ & 1,025 & 13.7 & 10.6 \\
$3\left(S_{3}\right)$ & 1,000 & 11.9 & 10.5 \\
$4\left(S_{4}\right)$ & 836 & 11.3 & 9.8 \\
\end{tabular}




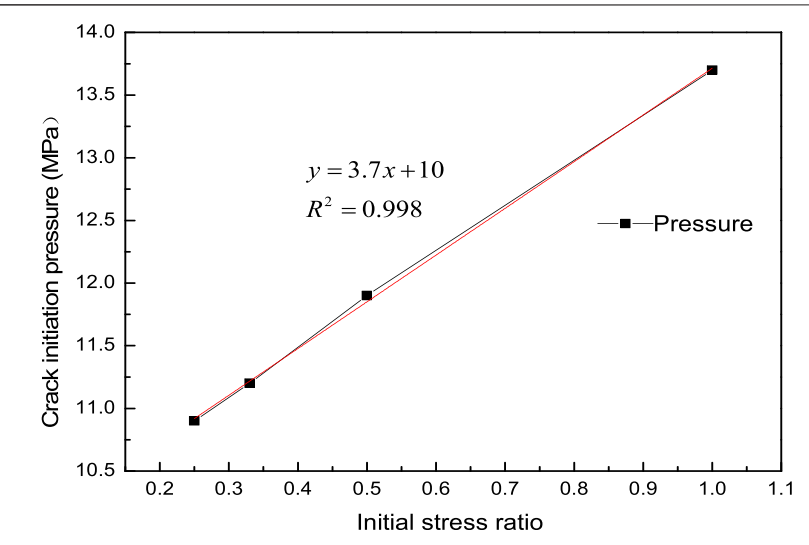

FIGURE 4 | The fitting relationship between crack initiation pressure and initial stress ratio.

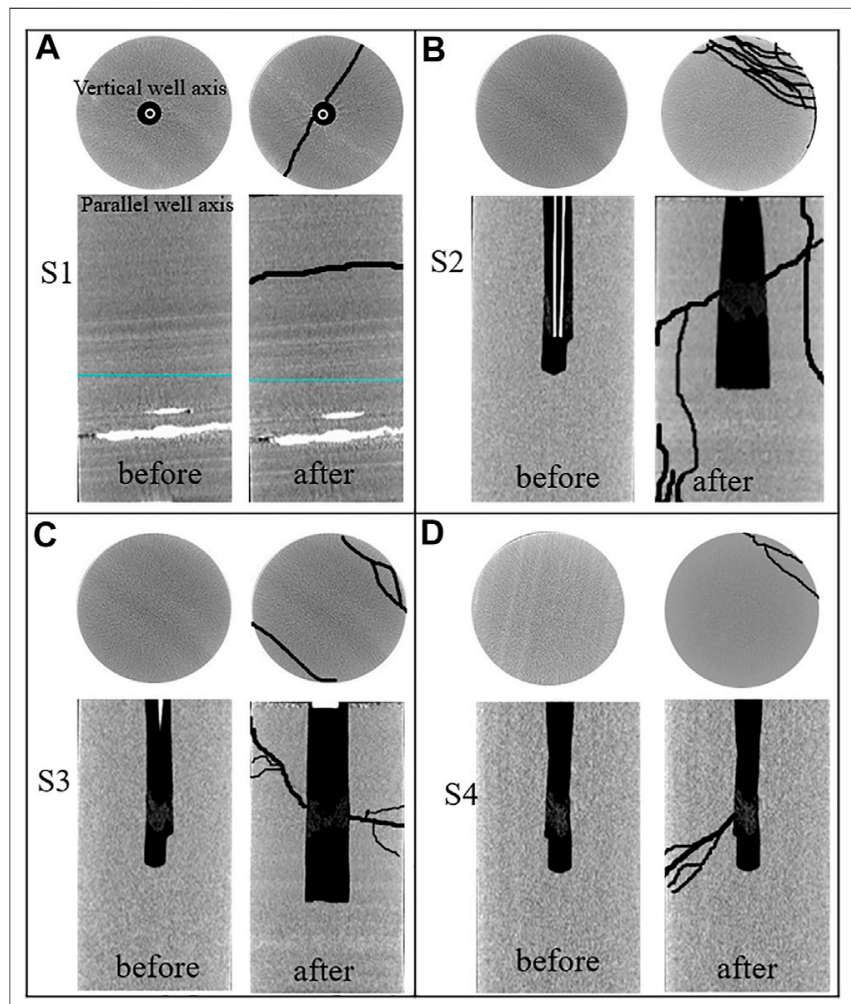

FIGURE 5 | CT scanning before and after the fracturing of four samples. (A) CT scanning image before and after fracturing of sample 1. (B) CT scanning image before and after fracturing of sample 2. (C) CT scanning image before and after fracturing of sample 3. (D) CT scanning image before and after fracturing of sample 4 .

specimens, which indicates that cracks spread from top and bottom, and the cracks in the specimens were connected. Furthermore, it was noted that the cracks mainly occurred along the direction of maximum principal stress, thus, cracks in the specimens after fracturing confirmed that supercritical $\mathrm{CO}_{2}$ fracturing can form a complex network of cracks in shale specimens.
To better understand the process of supercritical $\mathrm{CO}_{2}$ fracturing, the mechanism of the fracturing is described. From Figures 5B-D, we can see that cracks were first produced at the wall of the hole, and tensile failure occurred along the direction of maximum principal stress and accompanied by shear failure. The mechanical failure of the fracturing may relate to the developed stratification of shale and the characteristics of supercritical $\mathrm{CO}_{2}$ with low viscosity and high diffusivity. Compared to water, the low viscosity and high diffusion of supercritical $\mathrm{CO}_{2}$ make it easier to enter the micropore of the shale and make the cracks extend and turn along the weak bedding surface. These research findings are consistent with those of Chen L. Q. et al. (2015), who obersved that, due to the special properties of supercritical $\mathrm{CO}_{2}$ fracturing, it forms a complex fracturing networks more easily. In the process of crack propagation-due to the increase of free space-the phase change of $\mathrm{CO}_{2}$ from supercritical states to gas states was likely to have occurred. In addition, the compressibility of gaseous $\mathrm{CO}_{2}$ is much larger than supercritical $\mathrm{CO}_{2}$, so the phase change will produce gas explosions steeply, and is favorable for the production of complex fracture networks in shale specimens.

As shown in Figures 5B-D, it is interesting to note that new cracks at the same height of the shale specimens varied from different initial stress ratios. Specimen 2 had the largest number of cracks and the most complex fracture networks, while there were fewer cracks and fractures in Specimen 4, which had monotonous fracture networks. Under different stress state conditions, the crack initiation pressure and propagation direction varies with stress states and eventually forms different crack distributions and quantities, which show that the complexity of fracturing networks is affected by the initial stress ratio. In conclusion, these results show that cracks extend along the direction of maximum principal stress, and the cracks in shale form the main crack parallel to the direction of maximum principal stress after fracturing by supercritical $\mathrm{CO}_{2}$ fluid.

\section{DISCUSSION}

There are many theories relating to obtaining the pressure of crack initiation. One of the most classic formulae was proposed by Hubbert and Willis (1972). In this paper, according to the first strength theory, the initial rupture usually occurs (Zhao et al., 2015; Yang et al., 2019) at the hole wall. The tangential pressure at the hole wall may be defined as:

$$
\sigma_{\varphi}=\left(1+\frac{1}{\lambda}\right) \sigma_{c}-2\left(1-\frac{1}{\lambda}\right) \sigma_{c} \cos 2 \varphi-P(1-\beta)
$$

Where $P$ is the injection pressure; $\lambda$ is the initial stress ratio coefficient; $\beta$ is the seepage coefficient; $\sigma_{\mathrm{c}}$ is the horizontal stress.

The tensile strength of shale is far less than its compressive strength and the conditions for tensile failure or shear failure, so long as the tangential pressure reaches the tensile strength.

$$
\sigma_{\varphi}=-\sigma_{\mathrm{t}}
$$

Where $\sigma_{\mathrm{t}}$ is the tensile strength of the shale, the value of tensile stress is negative. The Eq. 1 taken into the Eq. 2 can be obtained: 


$$
P=\frac{\left(1+\frac{1}{\lambda}\right) \sigma_{\mathrm{c}}-2\left(1-\frac{1}{\lambda}\right) \sigma_{\mathrm{c}} \cos 2 \varphi+\sigma_{\mathrm{t}}}{(1-\beta)}
$$

Because $\cos 2 \varphi \in[-1,1]$, when shale is most likely to damage at $\cos 2 \varphi=1$ or $=-1\left(\varphi=0^{\circ}\right.$ or $\left.\varphi=90^{\circ}\right)$, the initiation pressure $\left(P_{\mathrm{b}}\right)$ of shale can be obtained:

$$
P_{\mathrm{b}}=\min \left\{\frac{\sigma_{\mathrm{t}}+\left(\frac{3}{\lambda}-1\right) \sigma_{\mathrm{c}}}{1-\beta}, \frac{\sigma_{\mathrm{t}}+\left(3-\frac{1}{\lambda}\right) \sigma_{\mathrm{c}}}{1-\beta}\right\}
$$

When $\lambda=1$, there are:

$$
P_{\mathrm{b}}=\frac{\sigma_{\mathrm{t}}+2 \sigma_{\mathrm{c}}}{1-\beta}
$$

It can be obtained according to this formula: $\cos 2 \varphi=1(\varphi=$ $\left.0^{\circ}\right)$ or $\cos 2 \varphi=-1\left(\varphi=90^{\circ}\right)$. At this point, there are two possible directions for crack initiation, one is horizontal and the other is vertical, the experimental results belong to the theory.

When $\lambda<1$, there are:

$$
\begin{gathered}
\frac{\sigma_{\mathrm{t}}+\left(3-\frac{1}{\lambda}\right) \sigma_{\mathrm{c}}}{1-\beta}<\frac{\sigma \mathrm{t}+\left(\frac{3}{\lambda}-1\right) \sigma_{\mathrm{c}}}{1-\beta} \\
P_{\mathrm{b}}=\frac{\sigma_{\mathrm{t}}+\left(3-\frac{1}{\lambda}\right) \sigma_{\mathrm{c}}}{1-\beta}
\end{gathered}
$$

At the same time, the fracture initiation will occur in the vertical direction of the fracture hole and can be concluded from the Eq. 7 . The smaller the initial stress ratio is, the smaller the initiation pressure. At the same time, the initial stress ratio is different, the stress distribution in the wellbore is different, and the location of the crack will be different so that the direction of crack propagation will not be the same, so the crack shape will be different. In short, the reliability of the experimental results is further verified by the theory.

The crack initiation orientation is affected by the maximum principal stress characteristics, the cracks are firstly initiated in the wellbore. The occurrence of expansion along with the maximum principal stress, eventually form a main crack in the vertical direction of minimum principal stress. Stress state will influence crack initiation orientation, crack morphology, crack distribution and crack initiation pressure. The study of the extraction and analysis of rock fracturing crack propagation through supercritical $\mathrm{CO}_{2}$ fracturing shale of low permeability under different triaxial stress conditions can provide a reference for reasonably selecting the fracturing layer of the shale gas reservoir and design of $\mathrm{CO}_{2}$ geological storage.

Shang, et al. (2018) used the local asymmetric fracturing stimulation method with small scale high-pressure fluids such as carbon dioxide, liquid nitrogen, water, and jet cutting, etc. to create slots and perforations for the aid of fracture initiation and orientation. The study results show that the asymmetric fracturing with slot and perforation orientation significantly increased fracture complexity. The research in this paper, in terms of the initial stress ratio and bedding effect of the crack propagation morphology and development process of rock, is consistent with the conclusions of Shang et al. (2018).

Compared with hydraulic fracturing, supercritical $\mathrm{CO}_{2}$ has low viscosity, meaning that it easily enters the very small pores and fractures in the shale specimen. The crack propagation process is not only more important for the microstructure and micro defects of shale specimens, but also more sensitive and helpful for the penetration of micro defects. The low viscosity characteristics of supercritical $\mathrm{CO}_{2}$ are helpful to crack propagation. In addition, during the process of crack propagation, the supercritical $\mathrm{CO}_{2}$ may also change from a supercritical state to a gaseous state. The compressibility of $\mathrm{CO}_{2}$ gas is so much greater than the supercritical state, that a sharp expansion of gas is produced during the process of phase transition. This is favorable to a weak surface or crack in the shale specimen. Therefore, the supercritical $\mathrm{CO}_{2}$ fracturing of shale simulation test method and test results established in this paper provides a new technical path for the development of anhydrous fracturing of shale gas.

\section{CONCLUSION}

Supercritical dioxide carbon fracturing experiments were carried by advanced multi-filed equipment under the condition of different stress states. Acoustic emission signal monitoring and crack CT scanning were used to analyze the fracturing crack propagation. The conclusions of this study are as follows:

1) When vertical stress is equal to horizontal stress, fracturing cracks propagate along the horizontal direction. When the vertical stress is greater than the horizontal stress, fracturing cracks propagate along the vertical extension. Supercritical $\mathrm{CO}_{2}$ fracturing can form a main crack in triaxial stress conditions in shale, with the main crack expansion occurring along the direction of maximum principal stress expansion.

2) Shale crack initiation pressure is always greater than horizontal stress, and reopening pressure is lower than initiation pressure. The initial stress ratio influences crack initiation and propagation pressure. Stress state can influence crack initiation orientation, crack morphology, crack distribution and crack initiation pressure. With the decrease of the stress ratio, the crack becomes less obvious.

3) The supercritical $\mathrm{CO}_{2}$ fracturing process can be divided into three representative stages: (a) the stage of pressure accumulation in the wellbore; (b) the stage of pump closure; and (c) the crack reopening stage. At the crack reopening stage, the crack reopens again and continues to extend to form a complex fracture network. Acoustic emission signal intensity directly reflects shale crack initiation, propagation, and the coalescence process.

\section{DATA AVAILABILITY STATEMENT}

The original contributions presented in the study are included in the article/Supplementary Material, further inquiries can be directed to the corresponding authors.

\section{AUTHOR CONTRIBUTIONS}

GL: Conceptualization, Writing - Original Draft, Funding acquisition, YZ: Resources, Formal analysis, Visualization, YC: Investigation, Visualization, Funding acquisition. 


\section{FUNDING}

This work was supported by the National Natural Science Foundation of China (No. 51904049); the China Postdoctoral Science Foundation (2021M693750); the Natural Science

\section{REFERENCES}

Brantley, S. L., Yoxtheimer, D., Arjmand, S., Grieve, P., Vidic, R., Pollak, J., et al. (2014). Water Resource Impacts During Unconventional Shale Gas Development: the Pennsylvania Experience. Int. J. Coal Geology. 126, 140-156. doi:10.1016/j.coal.2013.12.017

Chen, L. Q., Tian, S. C., Li, G. S., and Fan, X. (2015a). Initiation Pressure Models for Supercritical CO2 Fracturing and Sensitivity Analysis. J. Rock Soil Mech. 36, 125-131. doi:10.16285/j.rsm.2015.S2.016

Chen, Y., Nagaya, Y., and Ishida, T. (2015b). Observations of Fractures Induced by Hydraulic Fracturing in Anisotropic Granite. Rock Mech. Rock Eng. 48 (4), 1455-1461. doi:10.1007/s00603-015-0727-9

Gupta, A., Gupta, A., and Langlinais, J. (2005). Feasibility of Supercritical Carbon Dioxide as a Drilling Fluid for Deep Underbalanced Drilling Operation. Dallas, Texas: Society of Petroleum Engineers. doi:10.2118/96992-MS

Haimson, B., and FaIrhurst, C. (1967). Initiation and Extension of Hydraulic Fractures in Rocks. Soc. Pet. Eng. J. 7 (6), 310-318. doi:10.2118/1710-pa

Huang, F., Lu, Y. Y., Tang, J. R., Ao, X., and Li, L. W. (2015). On the Erosion of Shale Impacted by Supercritical Carbon Dioxide jet.[J]. J. Rock Mech. Eng. 34 (4), 787-794. doi:10.13722/j.cnki.jrme.2015.04.016

Hubbert, M. K., and Willis, D. (1972). Mechanics of Hydraulic Fracturing [j]. Trans. AIME. 18 (1), 369-390. doi:10.1080/14786435708241195

Ishida, T., Aoyagi, K., and Niwa, T. (2012). Acoustic Emission Monitoring of Hydraulic Fracturing Laboratory Experiment With Supercritical and Liquid $\mathrm{CO}_{2}[\mathrm{~J}]$. Geophys. Res. Lett. 39 (16). doi:10.1029/2012gl052788

Jin, X., Shah, S. N., and Mao, S. (2012). "Hydraulic Fracturing Model Based on Nonlinear Fracture Mechanics: Theory and Simulation," in SPE Annual Technical Conference and Exhibition, San Antonio, Texas.

Jin, X., and Shah, S. (2013). "Fracture Propagation Direction and its Application in Hydraulic Fracturing," SPE Hydraulic Fracturing Technology Conference, Texas. doi:10.2118/163832-MS

Kolle, J. J. (2000). “Coiled-Tubing Drilling With Supercritical Carbon Dioxide," in SPE/Petroleum Society of CIM International Conference on Horizontal Well Technology, Calgary. doi:10.2118/65534-MS

Lai, N., Ye, Z., LiuXiangjunYang, J., and Zhang, J. (2005). In House Study on Water Locking Damage of Tight Sand Gas Reservoirs With Low Permeability [J]. Nat. Gas Industry. 25 (4), 125-127. doi:10.1016/j.molcatb.2005.02.001

Middleton, R. S., Carey, J. W., Currier, R. P., Hyman, J. D., Kang, Q., Karra, S., et al. (2015). Shale Gas and Non-Aqueous Fracturing Fluids: Opportunities and Challenges for Supercritical CO2. Appl. Energ. 147, 500-509. doi:10.1016/ j.apenergy.2015.03.023

Schmidt, D. R., and Zoback, M. D. (1989). Poroelasticity Effects in the Determination of Minimum Horizontal Principal Stress in Hydraulic Fracturing Test-A Proposed Breakdown Equation Employing a Modified Effective Stress Relation for Tensile Failure[J]. Int. J. Rock Mech. Mining Sci. Geomechanics Abstr. 26 (6), 499-506. doi:10.1016/0148-9062(89)91427-7

Shang, D., Yin, G., Zhao, Y., Deng, B., Liu, C., Kang, X., et al. (2018). Local Asymmetric Fracturing to Construct Complex Fracture Network in Tight Porous Reservoirs During Subsurface Coal Mining: An Experimental Study. J. Nat. Gas Sci. Eng. 59, 343-353. doi:10.1016/j.jngse.2018.09.005
Foundation of Chongqing (General Program, No. cstc2019jcyj-msxmX0702); the Program for Natural Science Foundation of Hunan Province (No. 2021JJ40028), Research Program of Department of Education in Hunan Provincial (No. 19C1781).

Small, M. J., Stern, P. C., Bomberg, E., Christopherson, S. M., Goldstein, B. D., Israel, A. L., et al. (2014). Risks and Risk Governance in Unconventional Shale Gas Development. Environ. Sci. Technol. 48 (15), 8289-8297. doi:10.1021/ es502111u

Vengosh, A., Jackson, R. B., Warner, N., Darrah, T. H., and Kondash, A. (2014). A Critical Review of the Risks to Water Resources From Unconventional Shale Gas Development and Hydraulic Fracturing in the united states. Environ. Sci. Technol. 48 (15), 8334-8348. doi:10.1021/es405118y

Wang, H. (2011). Feasibility Analysis on Shale Gas Exploitation With Supercritical Co2. Pet. Drilling Tech. 39 (3), 30-35. doi:10.3969/ j.issn.1001-0890.2011.03.005

Xie, H., Li, X., Fang, Z., Wang, Y., Li, Q., Shi, L., et al. (2014). Carbon Geological Utilization and Storage in China: Current Status and Perspectives. Acta Geotech. 9 (1), 7-27. doi:10.1007/s11440-013-0277-9

Yang, D. X., Qi, L. I., and Wang, S. (2014). Numerical Analysis of Propagation of Pore Pressure Waves in Compressible Fluid Saturated Porous Media. Rock Soil Mech. 35 (7), 2047-2056. doi:10.16285/j.rsm.2014.07.001

Yang, H., Zhao, Y., Zhang., X., Liu, G., Du, X., Shang, D., et al. (2019). Supercritical Co2 Fracturing With Different Drilling Depths in Shale. Energy Sourc. A: Recov., Util., Environ. Eff. 18 (3), 1-20. doi:10.1080/ 15567036.2019.1673850

Zhao, Y., Cao, S., Li, Y., and Qin, L. (2015). The Analysis of Antireflection Range in Coal Seam Hydraulic Fracturing. J. Mining Saf. Eng. 32 (4), 644-650. doi:10.13545/j.cnki.jmse.2015.04.020

Zhou, J., Liu, G., Jiang, Y., Xian, X., Liu, Q., Zhang, D., et al. (2016). Supercritical Carbon Dioxide Fracturing in Shale and the Coupled Effects on the Permeability of Fractured Shale: An Experimental Study. J. Nat. Gas Sci. Eng. 36, 369-377. doi:10.1016/j.jngse.2016.10.005

Zubkov, V. V., Koshelev, V. F., and Lin'kov, A. M. (2007). Numerical Modeling of Hydraulic Fracture Initiation and Development. J. Min. Sci. 43, 40-56. doi:10.1007/s10913-007-0006-6

Conflict of Interest: YZ was employed by the company Sinohydro Bureau 8 Co. LTD.POWERCHINA.

The remaining authors declare that the research was conducted in the absence of any commercial or financial relationships that could be construed as a potential conflict of interest.

Publisher's Note: All claims expressed in this article are solely those of the authors and do not necessarily represent those of their affiliated organizations or those of the publisher, the editors, and the reviewers. Any product that may be evaluated in this article, or claim that may be made by its manufacturer, is not guaranteed or endorsed by the publisher.

Copyright (c) $2021 \mathrm{Liu}$, Zhao and Cheng. This is an open-access article distributed under the terms of the Creative Commons Attribution License (CC BY). The use, distribution or reproduction in other forums is permitted, provided the original author(s) and the copyright owner(s) are credited and that the original publication in this journal is cited, in accordance with accepted academic practice. No use, distribution or reproduction is permitted which does not comply with these terms. 